\title{
Scaling up action on the prevention and control of noncommunicable diseases in the WHO Eastern Mediterranean Region
}

\author{
Mahmoud Fikri ${ }^{1}$ and Asmus Hammerich ${ }^{2}$
}

${ }^{1}$ Former Regional Director, WHO Regional Office for the Eastern Mediterranean, Cairo, Egypt. ${ }^{2}$ Director, Division of Noncommunicable Diseases and Mental Health, WHO Regional Office for the Eastern Mediterranean, Cairo, Egypt.

Citation: Fikri M, Hammerich A. Scaling up action on the prevention and control of noncommunicable diseases in the WHO Eastern Mediterranean Region. East Mediterr Health J. 2018;24(1):3-4. https://doi.org/10.26719/2018.24.1.3

Copyright (C) World Health Organization (WHO) 2018. Some rights reserved. This work is available under the CC BY-NC-SA 3.0 IGO license (https:// creativecommons.org/licenses/by-nc-sa/3.o/igo)

Noncommunicable diseases (NCDs) are the leading causes of death worldwide. They are responsible for approximately $68 \%$ of global mortality each year, with cardiovascular diseases, cancers, diabetes, and chronic respiratory diseases being the four main NCD killers. It is estimated that annually, 16 million people die prematurely (before the age of 70) as a result of NCD (1). The majority of NCD deaths $(74 \%)$ occur in low- and middle-income countries, where this public health crisis is especially challenging due to severe social and economic conditions already faced (1).

In the Eastern Mediterranean Region (EMR), currently around $60 \%$ of deaths are attributed to NCDs. The Region also suffers from some of the highest rates of NCD-related risk factors, such as physical inactivity, obesity, tobacco, and high salt, sugar and fat intake (2). Despite this, with sound and committed national, regional as well as international efforts, the burden of NCDs in the Region could be controlled.

The Political Declaration of the High-level Meeting of the UN General Assembly on the Prevention and Control of NCD in September 2011 clearly identified these diseases as a threat to socioeconomic development, and called for inclusion of their prevention and control in all governmental programmes (3). The Declaration commits Member States to creating a clear governance structure integrating all aspects of NCD control; i.e. surveillance, prevention and quality health care. They have also recognized the need for multisectoral cooperation between health and non-health government agencies, private industry, academic institutions and civil and international organizations. Cross-governmental "health-in-all-policies" initiatives have recently gained momentum in several countries of the Region.

In May 2013, the World Health Assembly endorsed the WHO Global Action Plan for the Prevention and Control of NCDs 2013-2020. This Global Action Plan provides Member States, international partners and WHO with a road map and menu of policy options based on nine global NCDs targets, to be attained by 2025 , including the number one target: to achieve a $25 \%$ relative reduction in premature mortality from NCDs by 2025 .

Following these global commitments, a number of initiates have taken place at the regional level. One of the guiding documents is the Eastern Mediterranean
Regional Framework for Action on Noncommunicable Diseases. This framework was endorsed at the WHO Eastern Mediterranean Regional Committee in 2012, and includes 17 strategic interventions and 10 monitoring indicators, covering the areas of NCD governance, prevention, surveillance and healthcare. Moreover, NCDs are a priority area in the WHO Eastern Mediterranean Regional Director's Roadmap for 2017-21 (4). Progress is being monitored on an annual basis through development of country progress factsheets on NCDs. The factsheets provide an update for each of the 22 countries, on whether they are fully implementing, partially implementing or not implementing each of the progress 17 sub-indicators.

To date, seven countries in the Region are fully achieving over six of the sub-indicators; however, the remaining 15 countries are fully achieving less than onethird of the sub-indicators. Progress is slowest in the areas of planning and surveillance, and tobacco control. In addition, WHO Regional Office for the Eastern Mediterranean has developed a number of additional tools to scale up progress across the NCD agenda. These include: diabetes and cancer progress sheets; priority legal interventions to address NCDs in the Region; a framework to scale up mental health; a framework on NCD integration in primary health care; and a framework for cancer prevention and control.

In 2015, heads of states and governments committed themselves at the United Nations General Assembly to develop national responses for implementation of the 2030 agenda for Sustainable Development, which includes five goals related to NCDs, to be attained by 2030 , more commonly known as the " $33 \%$ reduction by 30" targets (5). The Sustainable Development Goal (SDG) agenda reinforces our work in the prevention and control of NCD and achievement of related targets in the Region.

However, despite an overall high political commitment, regional progress in implementing the UNPD is uneven and insufficient to achieve NCD global voluntary and SDG-related targets. Regional implementation challenges include: emergencies and political instability; competing development priorities and inadequate commitment; limited health system capacity; weak multisectoral and multi-stakeholder collaboration; incoherent policies and competing interests (industry and trade promoting unopposed 
marketing); and unsustainable funding and human resources. With WHO support and other partners, countries need to address those challenges to scale up their national responses and improve progress at three important milestones, namely 2018 - for the four time-bound commitments; 2025 - for the nine voluntary global targets; and 2030 - for reducing deaths from NCDs by one third. We must also ensure that these milestones are to be achieved through guidance by the regional framework and country tracking sheets. These are the tools for reviewing progress, catalyzing action and identifying areas for further work in the prevention of NCDs.

The good news is that there is now plenty of evidence of what works. It is up to countries to implement these "best buys" for NCD prevention and control, in their respective national context. The following interventions are recommended to lead the way forward in the EMR to achieve the NCD-related goals outlined for 2018, 2025 and 2030:

1. Scaling up implementation of all time-bound commitments and NCD voluntary targets, guided by the Regional Framework for Action, and related guidance and tools developed by WHO.

2. In the area of governance, a) including health-related SDGs and targets in national development policies, plans and strategies; b) setting national targets, endorsing and implementing multi-sectoral action plans; and c) discussing the current situation across government departments and civil society in order to identify gaps where technical support would be needed and engage the required stakeholders.

3. In the area of prevention a) fostering implementation of cost-effective interventions for the prevention and reduction of NCD risk factors; b) scaling up tobacco control measures (MPOWER) at the highest level and in a sustainable way; c) implementing the guidelines of Article 5.3 of the WHO Framework Convention for Tobacco Control, alongside the best buys to end tobacco industry influence; d) scaling up and taking proactive measures in the implementation of the regional action plan on reduction of salt, fat and sugar; e) enforcing implementation of the code of marketing for breast milk substitutes, and f) promoting physical activity through proven effective public health campaigns.

4. In the area of healthcare a) reorienting and strengthening health system to address NCDs, prioritizing cost-effective interventions, with a focus on strengthening NCD integration in primary healthcare (PHC), both in stable and emergency settings, and b) defining NCD service package to be integrated in PHC with adequate supplies of medicines, technologies and trained personnel.

5. In the area of surveillance a) strengthening NCD surveillance systems, focusing on the three pillars of surveillance: health outcomes, risk factors and national systems response; b) preparing for 3rd High-level Meeting of the UN General Assembly in 2018 by implementing monitoring systems to report on 10 progress indicators (using the latest NCD country capacity survey 2017); c) seeking to institutionalize the STEPs or an equivalent NCD risk factor survey (conduct a STEPs survey, if the last one was conducted prior to 2010), and d) institutionalizing NCD surveillance measures that can be conducted periodically.

In conclusion, good progress has been made in the EMR in important areas of NCD prevention and control. However, challenges remain and countries have to continue their efforts to meet expectations of the global and regional NCD agenda in 2018 and beyond. The WHO Eastern Mediterranean Regional Director's Roadmap for 2017-21, prioritizing NCDs, may provide further guidance on that path.

\section{References}

1. World Health Organization. Global status report on noncommunicable diseases 2014. Geneva: World Health Organization; 2014 (http://apps.who.int/iris/bitstream/9789241564854/1/148114/10665_eng.pdf?ua=1, accessed 18 January 2018).

2. WHO Regional Office for the Eastern Mediterranean (EMRO). Assessing national capacity for the prevention and control of noncommunicable diseases. Cairo: EMRO; 2016 (http://apps.who.int/iris/bitstream/1/250370/10665/EMROPUB_2016_EN_19168. pdf, accessed 18 January 2018).

3. United Nations General Assembly Sixty-sixth session. Political declaration of the high-level meeting of the General Assembly on the prevention and control of non-communicable diseases (resolution 2/66). New York: United Nations; 24 January 2012 (http:// www.who.int/nmh/events/un_ncd_summit2011/political_declaration_en.pdf, accessed 18 January 2018).

4. WHO Regional Office or the Eastern Mediterranean (EMRO). Roadmap of WHO's work for the Eastern Mediterranean Region 2021-2017. Cairo: EMRO; 2017 (http://applications.emro.who.int/docs/EMROPUB_19695_2017_EN.pdf?ua=1, accessed 18 January 2018).

5. United Nations General Assembly Seventieth session. Transforming our world: the 2030 agenda for sustainable development (resolution 1/70). New York: United Nations; 21 October 2015 (http://www.un.org/en/development/desa/population/migration/ generalassembly/docs/globalcompact/A_RES_1_70_E.pdf, accessed 18 January 2018). 